\title{
STRATEGI MITIGASI TERHADAP RISIKO PETANI MENGHADAPI ALIH FUNGSI LAHAN (Kelurahan Setianagara, Kecamatan Cibeureum, Kota Tasikmalaya, Jawa Barat)

\author{
MITIGATION STRATEGY IN DEALING WITH THE FARMERS' RISK OVER \\ LAND CONVERSION IN SETIANAGARA, CIBEUREUM DISTRICT, \\ TASIKMALAYA CITY, WEST JAVA
}

\author{
Nita Agresia Sijabat", Trisna Insan Noor \\ Program Studi Agribisnis, Fakultas Pertanian, Universitas Padjadjaran \\ *Email: nita16001@mail.unpad.ac.id \\ (Diterima 24-02-2020; Disetujui 04-05-2020)
}

\begin{abstract}
ABSTRAK
Strategi mitigasi merupakan suatu cara, teknik, taktik, atau siasat yang dilakukan sebagai tindakan preventif dalam pengurangan dan pencegahan dampak negatif akan suatu hal yang terjadi. Ketersediaan lahan sawah di Kelurahan Setianagara, Kecamatan Cibeureum, Kota Tasikmalaya, Provinsi Jawa Barat yang kini semakin langka akibat terjadinya alih fungsi lahan dan membuat petani kehilangan mata pencahariannya. Alih fungsi lahan menyebabkan berbagai risiko yang variatif yang menimbulkan kerugian bagi petani. Penelitian ini bertujuan untuk mengidentifikasi faktor-faktor prioritas yang mempengaruhi risiko petani terancam mengalihfungsikan lahannya dan menganalisis strategi mitigasi terhadap risiko petani sawah yang tepat untuk mengendalikan alih fungsi lahan sawah. Desain penelitian ialah penelitian kuantitatif dengan metode survei. Alat analisis menggunakan alat analisis deskriptif dan HOR (House of Risk). Hasil penelitian menunjukkan bahwa faktor-faktor prioritas yang mempengaruhi petani sehingga terancam mengalihfungsikan lahannya adalah adanya proyek pembangunan, belum legalnya perundangundangan, sistem waris, dan sulitnya pasokan air. Adapun strategi mitigasi petani sawah yang tepat untuk mengendalikan alihfungsi lahan di Kelurahan Setianagara, Kecamatan Cibereum, Kota Tasikmalaya, Provinsi Jawa Barat yaitu (1) implementasi rencana detail tata ruang; (2) penetapan LP2B; (3) pendampingan dan penyuluhan; dan (4) perbaikan irigasi.
\end{abstract}

Kata kunci: Strategi Mitigasi, Risiko, House of Risk (HOR), Alih Fungsi Lahan

\section{ABSTRAC}

The mitigation strategy defined as a method, a technique, or a tactic to reduce and or to prevent the negative impact of the things that could happen. The availability of the rice field in Setianegara, in the district of Cibereum, Tasikmalaya City, the Province of West Java is increasingly scarce due to the land conversion and make the farmers lose their job. This land conversion creates a lot of variety of risks and brings loss to the farmers. This research objective was to identify the priority factors that affect the risk of the farmers converse the land and to analyze the mitigation strategy over the rice field farmers to restrain the land conversion. The research design was quantitative research with survey methods. The analytical tools used in this research were the descriptive and House of Risk (HOR) analysis. The result of this research indicated that the priority factors that affected the farmers to converse the land were the building projects, unlegalized laws, the inheritance problem, and lacks of water resources. The mitigation strategy of the farmers that should be used to restrain the land conversion in Setianegara, Cibereum District, Tasikmalaya City, the Province of West Java should be : (1) planning implementation of the spatial detail, (2) establishing The LP2B: (3) assisting and counselling; and (4) improving the irrigation.

Keywords: Mitigation Strategy, Risk, House of Risk (HOR), Land Conversion 


\section{PENDAHULUAN}

Indonesia mengharapkan sektor pertanian menjadi penyokong perekonomian, tercemin dari nilai Produk Dosmestik Bruto (PDB) sektor pertanian yang tumbuh $3,7 \%$ dari tahun $2017^{1}$. Namun, kinerja sektor pertanian masih dihadapkan pada berbagai masalah diantaranya sumberdaya yang langka (lack of resources). Salah satu yang utama adalah semakin langkanya sumberdaya lahan pertanian (Isa, 2015). Petani Indonesia hanya menguasai lahan kurang dari 0,5 ha/keluarga (Isa, 2015).

Petani mengharapkan keuntungan yang besar agar dapat memenuhi kebutuhan keluarga dan mendapatkan kehidupan yang sejahtera. Namun, pada kenyataannya tidak sedikit petani mengalami kerugian karena risiko dan ketidakpastian yang dihadapinya. Petani dikatakan menghadapi risiko manakala mengetahui kemungkinan output yang akan diperoleh yang merupakan suatu ketidakpastian. Ketidakpastian yang direspon oleh petani hanya berdasarkan asumsi saja, dapat membuat respon tersebut tidak tepat sasaran. Respon petani yang tidak tepat sasaran membuat

\footnotetext{
${ }^{1}$ Detik.com. 2018. PDB Pertanian 2018 tumbuh 3,7\%, Kementan: Melebihi Target. www.detik.com/finance/berita-ekonomi-bisnis/d4545360/pdbpertanian tumbuh37kementanmelebihitarget
}

pertanian menjadi salah satu sektor dengan risiko yang tinggi (Rasmikayati, dkk, 2017).

Tingginya risiko pertanian memotivasi petani untuk beralih ke sektor lain agar memperoleh pendapatan yang lebih tinggi dengan profit yang lebih tinggi (Dadzie et al, 2012). Motivasi petani untuk beralih ke sektor lain juga akan menimbulkan kecenderungan petani dalam menjual dan mengalihfungsikan lahannya (Prayuda, dkk, 2013). Sejalan dengan hal tersebut, Kota Tasikmalaya sebagai salah satu kota di Provinsi Jawa Barat yang memiliki luas lahan pertanian yang cukup luas seperti pada Tabel 1 . Lahan tersebut mengalami tingkat konversi lahan yang cukup tinggi yang dapat mengancam ketahanan pangan Kota Tasikmalaya.

Pemerintah telah menetapkan UU No.41 tahun 2009 tentang Perlindungan Lahan Pertanian Pangan Berkelanjutan (LP2B) sebagai upaya menjaga ketersediaan lahan. Namun, data membuktikan bahwa masih terjadi konversi lahan dan konversi terbesar terjadi di Kecamatan Cibeureum (Tabel 2). Menurut penelitian Martunisa (2018), hal ini terjadi karena keterdekatan kecamatan tersebut dengan pusat kota serta adanya rencana pembangunan 
kecamatan tersebut menjadi pusat resiko bagi petani yang kemudian akan pendidikan Kota Tasikmalaya. Berbagai semakin mendesak petani untuk menjual faktor tersebut menjadi sumber timbulnya lahan pertaniannya.

Tabel 1. Luas Lahan Baku Sawah Menurut Kabupaten/Kota di Jawa Barat Tahun 2014-2016 (ha)

\begin{tabular}{clccc}
\hline No. & \multicolumn{1}{c}{ Kota/Kabupaten } & $\mathbf{2 0 1 4}$ & $\mathbf{2 0 1 5}$ & $\mathbf{2 0 1 6}$ \\
\hline 1. & Kabupaten Indramayu & 115.913 & 115.555 & 115.833 \\
2. & Kabupaten Karawang & 97.529 & 96.428 & 95.876 \\
3. & Kabupaten Sukabumi & 63.986 & 66.692 & 66.579 \\
4. & Kota Tasikmalaya & $\mathbf{5 . 9 8 6}$ & $\mathbf{5 . 9 4 7}$ & $\mathbf{5 . 9 0 4}$ \\
5. & Kota Banjar & 3.318 & 3.318 & 3.313 \\
6. & Kota Sukabumi & 1.532 & 1.486 & 1.464 \\
\hline
\end{tabular}

Sumber: BPS, 2017

Tabel 2. Perkembangan Luas Lahan Baku Sawah di 4 Kecamatan Kota Tasikmalaya Tahun 2014-2016 (ha)

\begin{tabular}{clcccc}
\hline No & Kecamatan & $\mathbf{2 0 1 4}$ & $\mathbf{2 0 1 5}$ & $\mathbf{2 0 1 6}$ & Luas Konversi \\
\hline 1. & Kawalu & 1.244 & 1.244 & 1.244 & - \\
2. & Cibeureum & $\mathbf{7 6 3 , 5}$ & $\mathbf{7 6 3 , 5}$ & $\mathbf{7 5 8 , 5}$ & $\mathbf{5}$ \\
3. & Mangkubumi & 1.134 & 1.134 & 1.132 & 2 \\
4. & Purbaratu & 499 & 499 & 494 & 5 \\
\hline & Jumlah & $\mathbf{3 6 4 0 , 5}$ & $\mathbf{3 6 4 0 , 5}$ & $\mathbf{3 6 2 8 , 5}$ & $\mathbf{1 2}$ \\
\hline
\end{tabular}

Sumber : Dinas Pertanian Kota Tasikmalaya, 2017

Setianagara yang merupakan salah satu kelurahan yang terdapat di Kecamatan Cibeureum, Kota Tasikmalaya, juga ikut merasakan dampak alih fungsi lahan. Petani di Kelurahan Setianagara mengetahui risiko yang diakibatkan pembangunan yang mulai berjalan di areal lahan yang digarap. Berbagai risiko akan dihadapi oleh petani, baik petani yang merupakan petani pemilik penggarap dan juga petani penggarap. Setiap risiko yang dihadapi sebaiknya diberikan tindakan antisipasi terhadap kerugian yang lebih besar yang akan dihadapi oleh petani.
Tindakan antisipatif atau preventif tersebut disebut juga dengan mitigasi. Secara umum, mitigasi adalah pengurang-an, pencegahan atau dapat juga dikatakan sebagai proses mengupayakan berbagai tindakan preventif untuk meminimalisasikan dampak negatif bencana yang akan terjadi (Noor, 2012). Harapannya selain menekan laju konversi lahan yang terjadi, perlu adanya upaya preventif atau antisipasi guna meminimalisir risiko yang timbul akibat faktor-faktor yang mempengaruhi risiko tersebut. Namun, pada kenyataan di lapangan, petani belum 
mengetahui tindakan apa yang akan dilakukan ketika terjadi alih fungsi lahan. Sehingga penelitian mengenai strategi mitigasi terhadap risiko petani menghadapi alih fungsi lahan dirasa tepat dilakukan di Kelurahan Setianagara yang merupakan salah satu kelurahan di Kecamatan Cibeureum, Kota Tasikmalaya.

\section{METODE PENELITIAN}

Penelitian ini menggunakan desain kuantitatif deskriptif. Metode penelitian yang digunakan adalah metode survei. Objek yang diteliti dalam penelitian ini adalah strategi mitigasi terhadap petani sawah. Tempat penelitian berada di Kelurahan Setianagara, Kecamatan Cibeureum, Kota Tasikmalaya, Jawa Barat. Tempat penelitian ditentukan secara sengaja (purposive).

Populasi yang digunakan dalam penelitian ini adalah petani pemilik penggarap dan petani penggarap lahan sawah di Kelurahan Setianagara, dimana lahan tesebut masuk ke dalam kawasan LP2B. Populasi yang didapatkan yaitu sebanyak 104 petani pemilik penggarap dan petani penggarap, sehingga didapatkan jumlah sampel sebanyak 51 orang. Teknik pengambilan sampel dengan menggunakan teknik probability sampling yaitu simple random sampling.

Data penelitian diperoleh dari data primer dan sekunder. Alat analisis dalam penelitian ini adalah analisi House of Risk (HOR) yang merupakan modifikasi dari Failure Modes and Effect of Analisys (FMEA), untuk memprioritaskan sumber risiko mana yang pertama dipilih untuk diambil tindakan yang paling efektif dalam rangka mengurangi potensi risiko dari sumber risiko (Ulfah, dkk, 2016). Terdapat 2 fase yang digunakan dalam melakukan pendekatan HOR (Pertiwi \& Susanty, 2017), yaitu:

(1) HOR 1 digunakan untuk menentukan tingkat prioritas agen risiko yang harus diberikan sebagai tindakan pencegahan.

(2) HOR 2 adalah prioritas dalam pengambilan tindakan yang dianggap efektif.

\section{HASIL DAN PEMBAHASAN}

\section{Analisis HOR 1}

HOR (House of Risk) Tahap 1 merupakan tahap awal mengidentifikasi kejadian risiko dan sumber risiko yang terdapat dalam faktor pendorong dan faktor penarik petani alih fungsi lahan. Proses identifikasi dilakukan dengan 
wawancara terhadap petani yang yang sudah dan akan alih fungsi lahan.

1. Faktor Pendorong

a. Sistem waris

b. Kurangnya pengetahuan untuk usaha

2. Faktor Penarik

a. Sulitnya pasokan air

b. Belum legalnya perundangundangan

c. Adanya proyek pembangunan

d. Pengembang e. Provokasi dari petani lain

f. Sektor lain yang lebih menjanjikan

Berdasarkan identifikasi risiko yang dilakukan terhadap setiap faktorfaktor penyebab alih fungsi lahan pertanian, maka dapat dikatakan bahwa risiko-risiko dapat menimbulkan. Berbagai kejadian risiko yang disebabkan oleh alih fungsi lahan disajikan pada Tabel 3.

Tabel 3. Daftar Kejadian Risiko Alih Fungsi Lahan

\begin{tabular}{lcc}
\hline \multicolumn{1}{c}{ Kejadian Risiko } & Kode & Skala Dampak (1-10) \\
\hline Menurunnya produksi pangan keluarga & E1 & 4,2 \\
Lahan terpecah-pecah & E2 & 2,5 \\
Lahan di bagi-bagi lalu di jual & E3 & 1,8 \\
kehilangan semangat (discourage) untuk berusahatani & E4 & 2,7 \\
Tidak ada upaya mempertahankan lahan & E5 & 2,3 \\
Petani kehilangan pekerjaan (pengangguran) & E6 & 2 \\
Petani alih profesi & E7 & 2,5 \\
Produksi menurun & E8 & 2,4 \\
Alih Komoditas & E9 & 2,2 \\
Petani menjual lahan & E10 & 2 \\
Pembangunan kawasan non pertanian semakin meningkat & E11 & 6,7 \\
Petani menghabiskan modal usaha yang sudah dimiliki & E12 & 2,6 \\
Petani tidak mengetahui menjalankan usaha & E13 & 2,9 \\
Menurunkan nilai sosial lahan & E14 & 2,9 \\
Petani menjual lahan & E15 & 2 \\
Petani beralih profesi & E16 & 2,5 \\
lahan beralihfungsi dari pertanian ke non pertanian & E17 & 1,8 \\
\hline
\end{tabular}

Sumber: Analisis data primer, 2019

Kejadian risiko yang memberikan dampak yang paling besar yang dirasakan oleh petani dalam menghadapi alih fungsi lahan, seperti yang dijelaskan pada Tabel 3. "Pembangunan kawasan non pertanian semakin meningkat" (E11) di Kelurahan Setianagara sehingga menyebabkan lahan pertanian semakin sempit. Pembangunan yang terdapat di Kelurahan Setianagara adalah pembangunan dan ekstensfikasi atau perluasan Sekolah Terpadu yaitu Pondok Pesantren Riyadlul Ulum Wadda'wah dan adanya pembangunan Landasan Udara Wiriadinata. 
Kejadian-kejadian risiko (Tabel 3), muncul berdasarkan penyebab yang menjadi agen risiko. Agen-agen risiko penyebab dampak dalam menghadapi alih fungsi lahan. Adapun agen-agen risiko disajikan pada Tabel 4.

Tabel 4. Daftar Agen Risiko Alih Fungsi Lahan

\begin{tabular}{llcc}
\hline Faktor Penyebab & \multicolumn{1}{c}{ Risk Agent (Sumber Risiko) } & Kode & $\begin{array}{c}\text { Kemungkinan } \\
\text { Kejadian (O) }\end{array}$ \\
\hline Faktor & Sistem waris & A1 & 4,5 \\
Pendorong & Kurang pengetahuan untuk usaha & A2 & 2,1 \\
\hline \multirow{5}{*}{ Faktor Penarik } & Sulitnya pasokan air & A3 & 2,9 \\
& Belum legalnya Per-UU Kota & A4 & 5 \\
& Adanya proyek pembangunan & A5 & 5,4 \\
& Pengembang & A6 & 2 \\
& Provokasi dari petani lain & A7 & 1,4 \\
& Sektor lain yang lebih menjanjikan & A8 & 1,8 \\
\hline
\end{tabular}

Sumber: Analisis data primer, 2019

Setiap pembobotan nilai yang muncul pada Tabel 4 berasal dari hasil wawancara dengan petani. Hasil identifikasi agen risiko menunjukkan terdapat 8 agen risiko yang terindentifikasi. Tingkat kemunculan (occurence) pada agen risiko yang tertinggi adalah adanya proyek pembangunan (A5).

Setelah mengetahui bobot nilai pada setiap agen risiko, data yang telah didapat selanjutnya dimasukkan ke dalam Tabel Pareto, yaitu pada Tabel 4 untuk mendapatkan nilai Aggregate Risk Potential (ARP) pada setiap agen risiko. Setiap nilai ARP yang didapat dilakukan perangkingan dari yang tertinggi sampai terendah, nilai ARP tertinggi menunjukkan agen risiko yang memiliki pengaruh pada petani dalam menghadapi alih fungsi lahan seperti yang terdapat dalam Tabel 5.

Tabel 5. Tabel Pareto

\begin{tabular}{ccccc}
\hline Risk Agent & ARP & Peringkat & \%ARP & \% Total Cum ARP \\
\hline A5 & 1408,86 & 1 & 36,57 & 38,57 \\
A4 & 710,5 & 2 & 18,44 & 55,01 \\
A1 & 474,75 & 3 & 12,32 & 67,34 \\
A3 & 416,73 & 4 & 10,83 & 78,15 \\
A6 & 375,52 & 5 & 11,02 & 87,90 \\
A8 & 322,56 & 6 & 8,37 & 96,27 \\
A7 & 76,16 & 7 & 1,98 & 98,25 \\
A2 & 67,41 & 8 & 1,75 & 100,00 \\
\hline Total & $\mathbf{3 8 5 2 , 4 9}$ & & $\mathbf{1 0 0 \%}$ &
\end{tabular}

Sumber: Analisis data primer, 2019 
Hasil perhitungan nilai ARP menunjukkan bahwa "adanya proyek pembangunan" (A5) dan "belum legalnya per-UU" (A4) merupakan agen risiko dengan nilai ARP tertinggi. Agen risiko yang sudah terindentifakasi dilakukan klasifikasi dengan menggunakan aturan pareto. Klasifikasi agen risiko bertujuan untuk memudahkan penentuan sumber risiko yang paling memiliki pengaruh sehingga penting untuk diberikan aksi mitigasi sebagai alternatif upaya dalam meminimalisir risiko dan kerugian yang timbul (Setyabudi, 2018). Menurut Ulfah (2016), pengklasifikasian agen risiko dilakukan berdasarkan aturan 80:20, sehingga agen risiko di klasifikasi menjadi 3 bagian, yaitu:

- Klasifikasi A: Agen risiko tingkat tinggi dengan jumlah 50\% dari bagian agen risiko secara keseluruhan.

- Klasifikasi B: Agen risiko tingkat sedang dengan jumlah $30 \%$ dari Tabel 6. Klasifikasi Agen Risiko

\begin{tabular}{cccccc}
\hline $\begin{array}{c}\text { Risk } \\
\text { Agent }\end{array}$ & ARP & Peringkat & \%ARP & $\begin{array}{c}\text { \% Total Cum } \\
\text { ARP }\end{array}$ & klasifikasi ABC \\
\hline A5 & 1408,86 & 1 & 36,57 & 36,57 & A (Risiko Tinggi) \\
A4 & 710,5 & 2 & 18,44 & 55,01 & B (Risiko Sedang) \\
\hline A1 & 474,75 & 3 & 12,32 & 67,34 & \\
A3 & 416,73 & 4 & 10,83 & 78,15 & C (Risiko Rendah) \\
\hline A6 & 375,52 & 5 & 11,02 & 87,90 & \\
A8 & 322,56 & 6 & 8,37 & 96,27 & \\
A7 & 76,16 & 7 & 1,98 & 98,25 & 100,00 \\
A2 & 67,41 & 8 & 1,75 & & \\
\hline
\end{tabular}

Total 3852,49 $100 \%$

Sumber : Analisis data primer, 2020 


\section{Analisis HOR II}

Agen risiko tinggi menjadi risiko prioritas yang diperoleh dari tahap sebelumnya. Agen risiko prioritas akan mendapatkan fokus penanganan dalam HOR 2. Dalam HOR 2 merumuskan tindak mitigasi yang tepat dalam penanganan agen risiko untuk meminimalisir dampak yang terjadi.

Berdasarkan strategi mitigasi yang merupakan hasil diskusi dengan petani, hasil observasi di lapangan, dan studi literatur yang efektif dalam menangani agen risiko prioritas, terdapat 9 usulan strategi mitigasi. Analisis hubungan antara agen risiko dan tindakan mitigasi dilakukan dengan memberikan nilai korelasi yaitu dimana 0 menunjukkan tidak ada korelasi sedangkan 1, 3, 9 masing-masing menunjukkam korelasi rendah, sedang dan tinggi.

Dalam mengetahui strategi aksi atau tindakan terhadap agen-agen risiko prioritas, penting untuk dilakukan penilaian strategi mitigasi dengan mempertimbangkan keefektifan dalam penerapan strategi. Keefektifan penerapan strategi mitigasi diperoleh dari persepsi petani dalam menerima setiap aksi yang ditawarkan dalam proses wawancara. Setelah dilakukan penilaian, maka dilakukan perangkingan terhadap dengan melihat hasil Effectiveness to Dificulty (ETD) untuk setiap preventive Action (PA) dalam Model HOR 2.

Tabel 7. Model HOR 2

\begin{tabular}{|c|c|c|c|c|c|c|c|c|c|c|}
\hline \multirow{2}{*}{$\begin{array}{c}\text { Risk } \\
\text { Agent } \\
\text { (Aj) }\end{array}$} & \multicolumn{9}{|c|}{ Preventive Action (PAk) } & \multirow{2}{*}{$\mathbf{A R P j}$} \\
\hline & PA1 & PA2 & PA3 & PA4 & PA5 & PA6 & PA7 & PA8 & PA9 & \\
\hline A5 & & & & 9 & & 1 & 3 & & 1 & 1408,9 \\
\hline A4 & & 3 & 1 & & 3 & & 9 & & & 710,5 \\
\hline A1 & 9 & & & & & & & & & 474,75 \\
\hline A3 & & & & & & & & 9 & & 416,73 \\
\hline Tek & 4227,8 & 2131,5 & 710,5 & 12679,7 & 2132,5 & 1408,8 & 10621,08 & 4226,6 & 1408,9 & \\
\hline Dk & 3 & 4 & 4 & 4 & 4 & 4 & 3 & 3 & 4 & \\
\hline ETDk & 1409,3 & 1532,9 & 177,6 & 3169,9 & 532,9 & 532,2 & 2655,3 & 1408,9 & 352,2 & \\
\hline $\mathbf{R k}$ & 3 & 5 & 9 & 1 & 6 & 7 & 2 & 4 & 8 & \\
\hline \multicolumn{11}{|c|}{ Sumber: Analisis data primer, 2019} \\
\hline & Penilaian & til & akan & mitis & & - $\mathrm{Kl}$ & fikasi & Str & gi & tigasi \\
\hline
\end{tabular}


dengan jumlah $50 \%$ dari bagian strategi mitigasi secara keseluruhan

- Klasifikasi B: Strategi mitigasi dengan keefektifan tingkat sedang dengan jumlah $30 \%$ dari bagian strategi mitigasi secara keseluruhan

- Klasifikasi C: Strategi mitigasi dengan keefektifan tingkat rendah dengan jumlah $20 \%$ dari bagian strategi mitigasi secara keseluruhan

Hasil penilaian tindakan mitigasi menghasilkan lima prioritas strategi mitigasi risiko yang di peroleh dari klasifikasi strategi mitigasi yang secara rinci yang disajikan pada Tabel 8 .

Tabel 8. Klasifikasi Strategi Mitigasi

\begin{tabular}{cclcccc}
\hline Rank & Kode & Strategi Mitigasi & ETD & \%ARP & $\begin{array}{c}\text { \% Total } \\
\text { Cum } \\
\text { ETD }\end{array}$ & Klasifikasi ABC \\
\hline 1 & PA4 & $\begin{array}{l}\text { Implementasi rencana } \\
\text { detail tata ruang }\end{array}$ & 3169,94 & 29,93 & 29,93 & A (tingkat keefektifan \\
tinggi)
\end{tabular}

Sumber: Analisis data primer, 2019

Tabel 8 menunjukkan hasil perhitungan dari HOR 2. Terdapat $55 \%$ strategi mitigasi yang termasuk ke dalam klasifikasi A, 26,61\% strategi mitigasi yang masuk ke dalam klasifikasi B, dan
18,39\% masuk ke dalam klasifikasi C. Setiap agen risiko prioritas dengan tindakan penanganannya dirangkum dalam Tabel 9.

Tabel 9. Daftar Strategi Mitigasi Risiko

\begin{tabular}{clll}
\hline Kode & \multicolumn{1}{c}{ Deskripsi Risk Agent } & Kode & \multicolumn{1}{c}{ Deskripsi PA } \\
\hline A5 & Adanya proyek pembangunan & PA4 & Implementasi Rencana detail tata ruang \\
A4 & Belum legalnya per-UU kota & PA7 & Penetapan LP2B \\
A1 & Sistem Waris & PA1 & Pendampingan dan Penyuluhan \\
A3 & Sulitnya pasokan air & PA8 & Perbaikan irigasi \\
\hline
\end{tabular}

Sumber: Analisis data primer, 2019 
Strategi mitigasi yang tepat sebagai tindakan penanganan priotitas yaitu "Implementasi rencana detail tata ruang (PA4)". Tindakan mitigasi kedua adalah "penetapan LP2B (PA7)". Selanjutnya adalah adanya tindakan "pendampingan dan penyuluhan (PA1)" serta " Perbaikan irigasi (PA8)".

\section{STRATEGI MITIGASI}

Strategi mitigasi penting untuk dilakukan terhadap risiko petani dalam menghadapi terjadinya alih fungsi lahan. Strategi mitigasi terhadap petani bertujuan untuk pengurangan serta pencegahan dampak negatif yang akan mengurangi kesejahteraan petani. Strategi mitigasi yang telah dirumuskan dan dianalisis berdasarkan identifikasi keefektifan penerapan setiap strategi diperoleh strategi mitigasi yang paling efektif untuk diterapkan di Kelurahan Setianagara. Strategi mitigasi yang tepat untuk dilakukan terhadap petani di Kelurahan Setianagara yaitu Implementasi Rencana Detail Tata Ruang, Penetapan LP2B, Pendampingan dan penyuluhan, dan perbaikan irigasi.

Menurut PerDa Tasikmalaya No.10 pasal 1 Tahun 2016 bahwa Rencana Detail Tata Ruang (RDTR) Kota Tasikmalaya adalah penjabaran dan pendetailan RTRW yang bersifat operasion al sebagai landasan di dalam mengeluarkan izin pembangunan ${ }^{2}$. Landasan hukum tentang rencana detail tata ruang yang telah ditetapkan dijadikan acuan dalam mengendalikan alih fungsi lahan yang terjadi pada areal yang tidak sesuai dengan RDTR. Implementasi RDTR ditetapkan dengan perencanaan yang matang dalam membagi setiap ruang wilayan menjadi ruang terbuka hijau dan ruang terbuka non hijau yang proporsional.

Rencana detail tata ruang yang telah membagi ruang wilayah menjadi ruang terbuka hijau dan ruang terbuka non hijau. Ruang terbuka hijau yang termasuk didalamnya LP2B yang telah ditetapkan oleh Pemerintah Kota Tasikmalaya. LP2B di Kelurahan Setianagara saat ini masih dalam tahap pengkajian. LP2B ditetapkan berdasarkan UU No.41 Tahun 2009 menjadi salah satu strategi mitigasi yang tepat diterapkan di Kelurahan Setianagara. Penetapan LP2B ini bertujuan agar petani dapat mempertahankan lahan yang dimiliki dan digarap. Penetapan LP2B yang akan menolong petani yang menjadi

\footnotetext{
${ }^{2}$ Wali Kota Tasikmalaya, Peraturan Daerah Kota Tasikmalaya Nomor $10 \quad$ Tahun 2016 http://www.jdih.setjen.kemendagri.go.id/files/kot a tasikmalaya $10 \quad 2016 . \mathrm{pdf}$
} 
korban alih fungsi lahan. Penerapan LP2B ketika terjadi alih fungsi lahan di suatu areal sawah, maka areal tersebut harus diganti seluas lahan yang beralih fungsi.

Penerapan LP2B dapat diikuti dengan adanya pendampingan dan penyuluhan dari pihak terkait seperti BPP yang tersedia di Kelurahan Setianagara, Kabupaten Cibereum. Pendampingan dan penyuluhan dapat bertujuan dalam mendorong semangat petani dalam berusahatani. Pendampingan dan penyuluhan juga dapat menjadi sumber informasi yang tepat bagi petani khususnya petani yang tidak dapat mengadopsi teknologi. Pendampingan dan penyuluhan menjadi sumber dalam penyampaian informasi mengenai bagaimana petani dapat mempertahankan lahannya sehingga petani tidak mudah melepaskan lahannya.

Lahan sawah di Kelurahan Setianagara masih terdapat areal yang belum menggunakan irigasi teknis perlu untuk diperhatikan. Irigasi yang lancar mendorong petani untuk dalam bertahan dalam kondisi cuaca yang tidak menentu. Perbaikan irigasi menjadi salah satu strategi mitigasi yang tepat bagi petani, terutama saat musim kemarau panjang. Irigasi yang baik membantu mensejahterahkan kehidupan petani karena lahan dapat diusahakan sepanjang tahunnya.

Penerapan strategi mitigasi yang tepat akan meminimalisir atau mencegah dampak negatif terhadap petani di Kelurahan Setianagara. Petani tidak akan kehilangan lahan dan semangat dalam berusahatani, sementara lahan sawah akan terjaga ketersediaannya.

\section{KESIMPULAN DAN SARAN}

KESIMPULAN

1. Faktor-faktor prioritas yang mempengaruhi petani sehingga terancam mengalihfungsikan lahannya adalah adanya proyek pembangunan, belum legalnya perUU, sistem waris, dan sulitnya pasokan air.

2. Strategi mitigasi petani sawah yang tepat untuk mengendalikan alihfungsi lahan di Kelurahan Setianagara, Kecamatan Cibereum, Kota Tasikmalaya, Provinsi Jawa Barat yaitu (1) implementasi rencana detail tata ruang; (2) penetapan LP2B; (3) pendampingan dan penyuluhan; dan (4) perbaikan irigasi.

\section{SARAN}

1. Pemerintah Kota Tasikmalaya sebaiknya merealisasikan Rencana 
Detail Tata Ruang yang sudah ditetapkan sebelumnya, sehingga pembangunan di areal sawah yang tidak sesuai dengan implementasi RDTR dapat dikendalikan serta ruang terbuka hijau masih terjaga ketersediaannya.

2. Sebaiknya Pemerintah Kota Tasikmalaya segera menetapkan LP2B sehingga dapat direalisasikan dan disosialisasikan kepada seluruh pihak yang bersangkutan, salah satunya adalah pemilik lahan di Kelurahan Setianagara.

3. Penetapan LP2B kepada petani harus diberikan perhatian oleh pihak stakeholder dengan pemberian insentif dan disinsentif kepada petani yang menggarap lahan, baik petani pemilik penggarap maupun petani penggarap saja.

\section{UCAPAN TERIMAKASIH}

Ucapan terimakasih penulis sampaikan kepada seluruh dosen dan staf Fakultas Pertanian Universitas Padjadjaran, juga kepada Ir. H. Dede Sudrajat, M.P. dan seluruh pihak yang terlibat yang turut memberikan kontribusi pada saat penelitian ini berlangsung.

\section{DAFTAR PUSTAKA}

Dadzie, S.K.N, Acquah, H. de-Graft. (2012). Attitudes Toward Risk and Coping Responses: The Case of Food Crop Farmers at Agona Duakwa in Agona East District of Ghana. International Journal of Agriculture and Forestry, 2(2): 2937. doi: 10.5923/j.ijaf.20120202.06.

Isa, I. (2015). Strategi Pengendalian Alih Fungsi Lahan Pertanian. Jakarta: Badan Pertahanan Nasional.

Noor, D. (2012). Pengantar Mitigasi Bencana Geologi. Bogor: Pakuan University Press. Palar

Pertiwi, Y. E., \& Susanty, A. (2017). Analisis Strategi Mitigasi Resiko Pada Supply Chain Cv Surya Cip Dengan House Of Risk Model.

Prayuda, E. S., Sihombing, L., \& Kesuma, S. I. (2013). Dampak Alih Fungsi Lahan Sawah dan Strategi Mitigasinya Terhadap Program Swasembada Beras Di Kabupaten Asahan (Studi Kasus: Kecamatan Setia Janji, Kabupaten Asahan). Journal of Agriculture and Agribusiness Socioeconomics, 2(12): 1-15.

Rasmikayati, E., Sulistiyowati, L., \& Saefudin, B. . (2017). Risiko Produksi dan Pemasaran Terhadap Pendapatan Petani Mangga: Kelompok Mana yang Paling Berisiko, Mimbar Agribisnis 3(2): 105-116.

Setyabudi, A. G., (2018). Sistem Pendukung Pengambilan Keputusan Cerdas Manajemen Risiko Rantai Pasok Komoditas Belimbing. Skripsi. Institut Pertanian Bogor. Bogor.

Ulfah M. (2016). Rancang bangun model manajemen risiko rantai pasok gula rafinasi. Disertasi. Institut Pertanian Bogor. Bogor. 